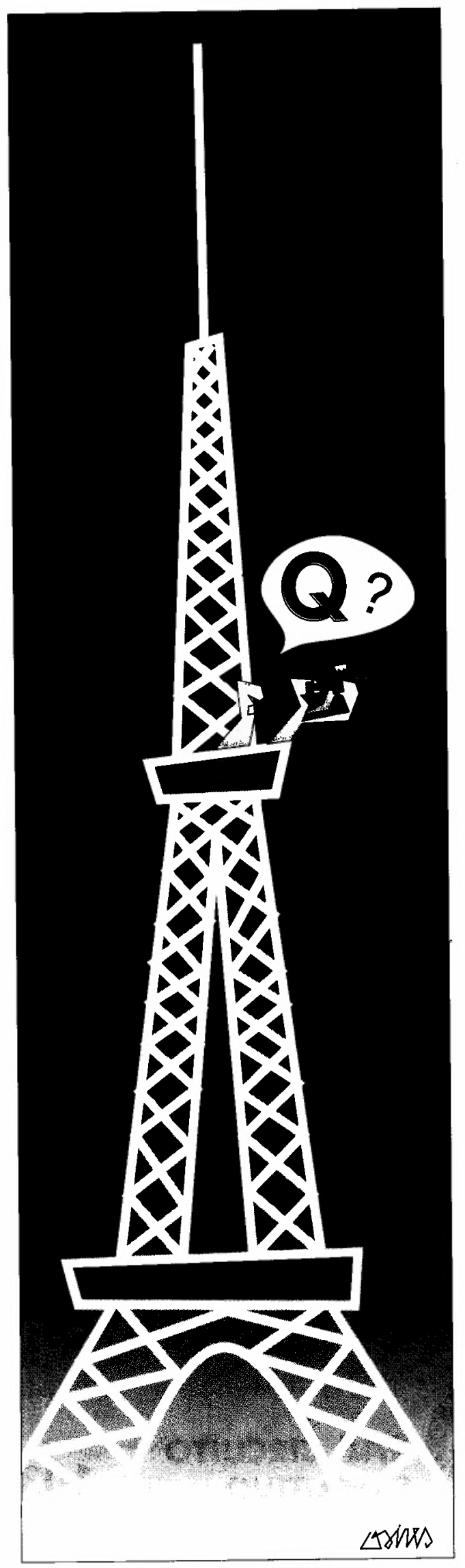

\section{OS CÍRCULOS DE QUALIDADE SÃO AINDA UM TEMA ATUAL?}

\author{
$\star$ Françoise Chevalier
}

Evolução dos Círculos de Qualidade na França, através de pesquisa em doze empresas.

Quality Circles development in France, through research in twelve firms.
Artigo originalmente publicado na revista Banque Stratégie, sob o título Les cercles de qualité soint-ils encore d'actualité?, $n$. 91, janeiro/1993, Paris.
PALAVRAS-CHAVE:

círculos de qualidade, mudança organizacional, qualidade total, estratégia, recursos humanos, organizaçōes francesas, administração participativa, produtividade, administração por objetivo.

\section{KEY WORDS:}

quality circles, organizational change, total quality, strategy, human resources, French companies, participative management, productivity, management by objectives.

$\star$ Professora Adjunta do Departamento de Administração e Recursos Humanos da HEC - École des Hautes Études Commerciales, Paris, França.

São Paulo, v. 35, n. 4, p. 8-14 
U m Círculo de Qualidade é formado por um grupo de voluntários, que se reúnem regularmente com o seu superior hierárquico direto, tendo como objetivo levantar os principais problemas encontrados no trabalho e analisálos, propondo e implementando soluções. Esta análise é feita em cinco etapas: a. definição dos objetivos; b. análise dos problemas; c. proposição de soluções; d. elaboração de um plano de ação (projeto-piloto) adequado aos objetivos propostos; e e. implementação e readequação do plano.

Após dez anos de existência na França, o que aconteceu com os Círculos de Qualidade? Terão desaparecido completamente, virando-se assim mais uma página da história da Administração de Empresas, ou continuam funcionando? Como continuam funcionando, ou quais foram as causas de sua extinção? A fim de responder a estas e outras questóes, iniciamos no começo dos anos 80 uma pesquisa longitudinal de acompanhamento do lançamento e do desenvolvimento dos Círculos de Qualidade na França. Esta pesquisa foi realizada nos setores secundário e terciário, reunindo doze empresas de médio porte ( 800 a 1.200 empregados), pioneiras no lançamento de Círculos de Qualidade. Além do pioneirismo, estas empresas têm em comum o fato de que mantiveram Círculos de Qualidade ativos durante um longo período. Desta forma, durante sete anos, realizamos um trabalho de acompanhamento, fazendo mais que 300 entrevistas com os diretores das empresas e com os executivos de diferentes niveis hierárquicos, tanto no setor administrativo quanto no setor operacional. Analisamos também inúmeros da-

\section{Gráfico 1}

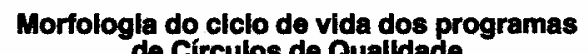
de Círculos de Qualldade

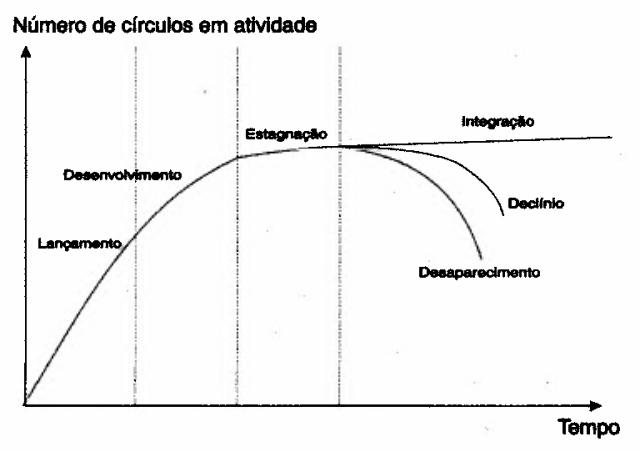

dos obtidos por meio da observação dos cursos e treinamentos dados aos executivos, da participação às reuniões dos Círculos de Qualidade e dos congressos organizados pelas empresas.

\section{MORFOLOGIA DO CICLO DE VIDA DOS CÍRCULOS DE QUALIDADE}

Constatou-se, por meio desta pesquisa, a existência de um verdadeiro ciclo de vida dos Círculos de Qualidade (CQ). Na primeira fase, as empresas costumam implantar de forma prudente os primeiros Círculos de Qualidade, observando os primeiros resultados. Normalmente esta fase é seguida por uma fase de entusiasmo, na qual o programa se desenvolve rapidamente. Após os primeiros resultados positivos, as empresas investem mais e aumentam consideravelmente o número de Círculos. Observa-se, no entanto, que após este período de entusiasmo e euforia inicia-se um período de declínio, que provoca duas conseqüências diferentes: ou os Círculos de Qualidade extinguem-se de uma vez, ou sobrevivem, integrando-se ao sistema. Cada uma destas fases tem características próprias, que variam de empresa para empresa. Enquanto uma fase durava um ano e meio em uma empresa, poderia durar dois anos em outra. Os dados relativos às diferentes fases dos Círculos de Qualidade franceses foram comprovados em outros países, como os Estados Unidos e a Inglaterra: aí, os Círculos de Qualidade evoluíram da mesma forma que na França, ou seja, por meio de um ciclo de vida típico, que, em média, durou sete anos (ver gráfico 1).

De fato, no início as empresas costumam implantar poucos Círculos de Qualidade $e$ as dificuldades são resolvidas caso a caso. Os bons resultados obtidos nesta primeira fase incentivam a empresa $a$ investir mais na implantação de novos Círculos, intensificando o programa. Desta forma, surgem rapidamente novos Círculos de Qualidade, iniciando-se a segunda fase, a da euforia e do entusiasmo. Durante este período, a empresa costuma reforçar este ambiente positivo, difundindo, através de uma estratégia de comunicação especial, os bons resultados do programa e incentivando os empregados a partici- 


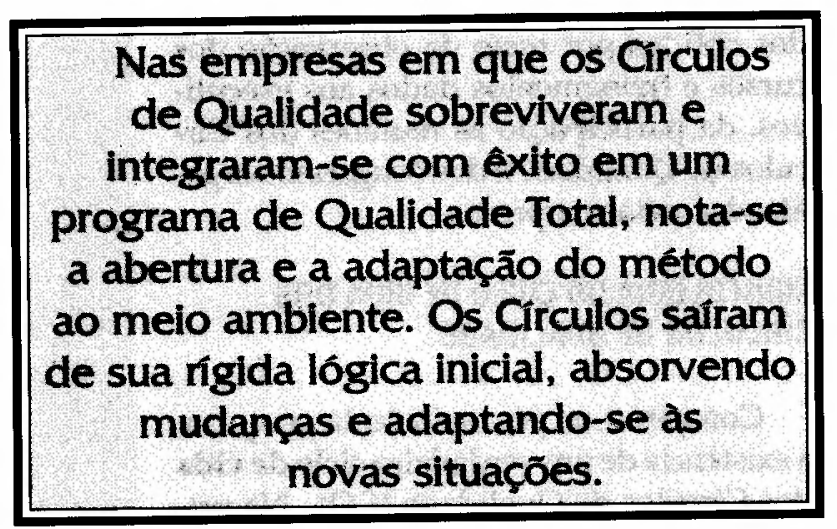

parem como voluntários. Os participantes dos Círculos de Qualidade costumam mostrar-se satisfeitos e motivados, em um entusiasmo crescente que chega ao seu ponto máximo antes de iniciar-se a terceira fase, caracterizada pelo declínio e pela estagnação. Um dos primeiros efeitos deste declínio são os inúmeros problemas que se apresentam nesta fase, como, por exemplo, o ceticismo dos executivos, principalmente dos que pertencem aos niveis hierárquicos intermediários, que tentam bloquear o funcionamento dos Círculos de Qualidade. Em alguns casos, esta fase de declínio tem como conseqüência o desaparecimento completo do programa. Em outros casos, os Círculos de Qualidade resistem e "vão sobrevivendo". Na realidade, neste caso, a fase do declínio prolonga-se indefinidamente e o programa continua, mas de forma bem restrita. Entretanto, nem sempre os Círculos de Qualidade evoluem desta forma. Em algumas empresas eles se adaptam às nnovas circunstâncias e vencem a fase de declínio, sendo efetivamente integrados ao sistema.

O interessante é que o ciclo de vida dos Círculos de Qualidade é o mesmo para as doze empresas pesquisadas, apesar de usarem diferentes métodos para implementar os programas, de terem organizaçóes distintas e de atuarem em setores diferentes. A descrição e a compreensão da evolução dos Círculos de Qualidade mostra-se fundamental para esclarecer este fenômeno ${ }^{1}$.

1. CHEVALIER, $F$. The quality movement in France: a passing fad or a new mode of management?, Quality Forum, v. 17, juin 1991; _ _ Cercles de qualité et changement organisationnel. Paris, Economica, 1991.

\section{O DESAPARECIMENTO DOS CÍRCULOS DE QUALIDADE}

Em duas empresas pesquisadas, os problemas provocados pelo desenvolvimento dos Círculos de Qualidade aumentaram consideravelmente e eles foram extintos. Nestes dois casos, a crescente oposição de alguns grupos organizacionais, além da redução do tempo e dos meios fornecidos pela empresa aos participantes, foi decisiva para este desfecho. Conseqüentemente, os comitês de orientação do programa de Círculos de Qualidade foram dissolvidos e os consultores e gerentes que o apoiavam (os "facilitadores") foram alocados em outros setores. Os empregados que eram voluntários e membros ativos do programa não tiveram nenhuma outra atividade de caráter participativo para substituir os Círculos de Qualidade. Houve um declínio na participação dos empregados e o sistema tornou-se mais rígido.

Nestes dois casos, houve uma concentração de Círculos de Qualidade somente em alguns setores das empresas, ficando outros setores ausentes do programa, principalmente os ligados aos serviços técnicos e administrativos (contabilidade, informática, compras, pessoal etc.). Mesmo assim, as duas empresas que extinguiram os Círculos de Qualidade tiveram um resultado econômico extremamente positivo com o programa. No primeiro caso, o programa custou 5.240.000 francos, produzindo um lucro bruto de 6.171.000 francos, ou seja, um lucro líquido de 931.000 francos. No segundo caso, constata-se o mesmo fato: a empresa teve um ganho considerável. A rentabilidade do programa não era, então, o fator determinante na extinção dos Círculos de Qualidade. A direção das empresas, nos dois casos, para justificar a sua extinção, assumiu a posição da gerência média, que se opunha ao programa desde o começo, afirmando que era um efeito de moda e um peso para a estrutura organizacional. Os "facilitadores", gerentes e consultores que tinham sido responsáveis pela implantação dos Círculos de Qualidade, assumiram uma posição contrária à da diretoria, reiterando que sua participação no programa de Círculos de Qualidade tinha sido uma experiência rica do ponto de vista pessoal e empresarial e que lamentavam a sua extinção. Os empregados que voluntariamente haviam participado ativamente do programa tinham, no entanto, reaçóes ambíguas: de um lado estavam decepcionados com o fim dos Círculos de Qualidade, mas ao mesmo tempo 
estavam aliviados com o fim de uma experiência que tinha se tornado pesada e difícil de ser vivida, devido aos problemas gerados pela insatisfação da gerência média e pelo corte dos recursos disponíveis.

\section{OS CÍRCULOS DE QUALIDADE QUE SOBREVIVERAM AO DECLINIO}

Em outras empresas, no entanto, os Círculos de Qualidade resistiram ao período de declínio e não foram extintos. Em alguns casos, apesar de sobreviverem, os Círculos de Qualidade caíram em um marasmo enorme, funcionando sempre da mesma forma. Não se investia no programa, não se inovava, pode-se afirmar que apenas sobreviviam, mas sem nenhuma perspectiva de desenvolvimento. Para os membros ativos do programa, essa situaçāo não era fácil.

Diversos depoimentos mostram, entretanto, que os Círculos de Qualidade continuavam a exercer uma funçāo importante: desenvolver nos indivíduos um comportamento mais ativo, motivando-os a refletir e a analisar o próprio trabalho e aumentando sua autonomia.

O sentimento geral provocado por esta estagnação era de que a empresa deveria investir mais no desenvolvimento do programa de Círculos de Qualidade a fim de dinamizar a organização.

\section{A INTEGRAÇ̃̃O DOS CÍRCULOS DE QUALIDADE AO SISTEMA}

As empresas que conseguiram integrar os Círculos de Qualidade no seu funcionamento cotidiano foram as que deram flexibilidade a eles, vencendo a rigide $z$ do sistema. Nestas empresas, o número de Círculos de Qualidade continuou a aumentar sempre, mesmo que em alguns períodos esse aumento fosse moderado. Os grupos continuavam a obter resultados, e o programa tinha uma boa rentabilidade. Tendo conseguido superar definitivamente a fase de declínio, os participantes dos Círculos mostravam-se confiantes, uma vez que o programa era aceito pela maioria dos empregados e gerentes, não encontrando as fortes resistências características dos outros casos. Tal resultado deve-se a três fatos abordados a seguir.

\section{A implantação de um programa de} Qualidade Total durante a fase de declínio dos Círculos de Qualidade

Estas empresas optaram pela implementação de um programa de Qualidade Total que permitiu a integração dos Círculos de Qualidade a um sistema maior, evitando o aumento de resistências e conflitos provocados por eles, o que permitiu a superação da fase de declínio. O fato de os Círculos de Qualidade se concentrarem no início somente em alguns setores das em-

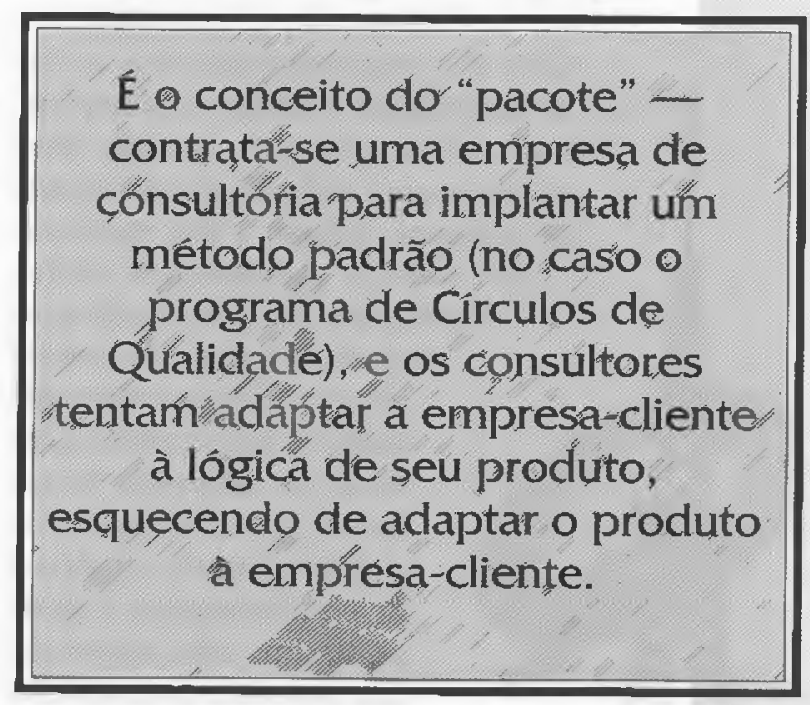

presas gerou conflitos entre os gerentes de diferentes departamentos, porque estes lutavam pelos recursos, pelo poder e pelo prestígio ligados à implementação do programa. Ao criar o programa de Qualidade Total, aumentando os investimentos neste setor, integrando vários métodos e distribuindo os recursos mais uniformemente, a diretoria destas empresas obteve sucesso, impedindo a extinção dos Círculos de Qualidade, que foram integrados eficazmente ao novo sistema. Os gerentes dos setores excluídos do programa de Círculos de Qualidade obtiveram desta forma novas responsabilidades ligadas à aplicação de outros métodos, e os setores que já estavam envolvidos com os Círculos de Qualidade continuaram esse programa sem as resistências do período de declínio, consolidando sua participação. 
O real envolvimento da direção das empresas na implementação do programa de Qualidade Total e a criação de uma organização eficaz

Nos casos em que a direção da empresa realmente se dedicou à elaboração do programa de Qualidade Total, organizando sua implementação de forma eficaz, a empresa pôde superar o período de declínio dos Círculos de Qualidade com êxito, pois o sistema de Qualidade Total foi realmente consolidado. Neste caso, além do real envolvimento da direção, foram necessários enormes investimentos e a criação de uma estrutura adequada à administração do programa de Qualidade Total, envolvendo diversos departamentos.

Uma das empresas estudadas investiu 220 milhões de francos na implantação deste programa, criando uma estrutura composta de representantes de todos os setores. Cada representante deveria coordenar os chefes das equipes de melhoria de qualidade, seguindo de perto $o$ progresso delas e transmitindo as informações à direção da empresa. Desta forma, os resultados eram controlados em diversos níveis hierárquicos. Criouse, assim, uma estrutura que permitiu uma divisão mais uniforme do poder $e$ dos recursos ligados ao controle dos resultados. Isto nâo acontecia antes, quando somente os chefes dos Círculos de Qualidade faziam este acompanhamento. Ao se destruir o monopólio dos "facilitadores" e dos gerentes dos Círculos de Qualidade, encontrou-se a solução para evitar a extinção do programa. Diminuindo os conflitos entre participantes e não-participantes dos Círculos de Qualidade, o programa começou a se desenvolver novamente em todas as empresas pesquisadas, ganhando um novo folêgo. A principal função dos Círculos de Qualidade para as empresas foi mantida: envolver os empregados nos objetivos da empresa com a implantação de um sistema participativo.
A substituição de um reconhecimento "simbólico" para um reconhecimento mais concreto dos Círculos de Qualidade

Com o desenvolvimento dos programas de Qualidade Total burocratizou-se o sistema, criando-se cargos e formalizando-se o controle dos resultados ligados à qualidade dos produtos e serviços. A criação de uma estrutura formal ligada ao "sistema de qualidade" permitiu o reconhecimento mais efetivo dos resultados obtidos pelos Círculos de Qualidade, através de maiores investimentos da empresa no programa e da formalização de um plano de carreira mais detalhado. Antes de integrar os Círculos de Qualidade ao programa de Qualidade Total, o reconhecimento dado aos seus participantes era essencialmente simbólico: os participantes apresentavam seus resultados à diretoria em cerimônias especiais, ganhavam prêmios e troféus por sua atuação, eram prestigiados pela comunicação interna da empresa, mas não tinham um plano de carreira, e o fato de participarem dos Círculos de Qualidade também não tinha maior impacto em relação a seus salários. O fato de pertencer aos Círculos de Qualidade passou a ser levado em conta na avaliação do funcionário. Em alguns casos, iniciou-se o pagamento por produtividade, motivando muitos funcionários a aderirem ao programa.

\section{CONCLUSÃO}

As empresas em que os Círculos de Qualidade desapareceram se caracterizavam por não integrarem os diversos métodos que aplicavam para melhorar a qualidade de seus produtos e serviços. Os participantes dos Círculos de Qualidade ficavam, assim, isolados, realizando eventuais apresentaçōes para a direção, mas o seu trabalho perdia cada vez mais o impacto conquistado no período inicial. Os Círculos de Qualidade continuavam a ser dirigidos de forma rígida, sem se adaptarem às novas situaçōes. A falta de flexibilidade de seu programa reforçava ainda mais os conflitos com os indivíduos que deles não participavam, uma vez que não havia concessões e negociações possíveis: os Círculos de Qualidade fechavam-se em si mesmos, tornando-se rígidos e isolando-se dos ou- 
tros grupos organizacionais. Quanto mais problemas, mais os Círculos se tornavam rígidos para afirmar sua lógica de funcionamento inicial, fechando-se, e mais esta atitude aumentava os problemas e os conflitos, em um círculo vicioso que conduziu ao seu desaparecimento definitivo.

Nas empresas em que os Círculos sobreviveram e integraram-se com êxito em um programa de Qualidade Total, nota-se a abertura e a adaptação do método ao meio ambiente. Os Círculos saíram de sua rígida lógica inicial, absorvendo mudanças e adaptando-se às novas situações. Houve um processo de negociação com os outros grupos organizacionais: os facilitadores e dirigentes dos Círculos de Qualidade aceitaram dividir os recursos e o prestígio ligados ao sistema de qualidade, quebrando o seu monopólio, o que se concretizou através da criação do sistema de Qualidade Total, que englobou vários outros métodos. A evolução tecnológica apressou também a criação deste sistema integrado, mas o fato de os membros dos Círculos de Qualidade se mostrarem flexíveis e aceitarem as transformações foi vital para sua sobrevivência.

Nota-se, desta forma, a existência de dois modelos de mudança organizacional completamente distintos: um deles baseiase na aplicação rígida de um método que tem seus princípios, suas regras e sua estrutura formal própria, que serão mantidas inalteradas até o fim. É o conceito do "pacote" - contrata-se uma empresa de consultoria para implantar um método padrão (no caso o programa de Círculos de Qualidade), e os consultores tentam adaptar a empresa-cliente à lógica de seu produto, esquecendo de adaptar o produto à empresa-cliente. Tenta-se, assim, implantar um mesmo "pacote" , um mesmo método, em diversas empresas, da mesma forma, sem levar em conta as diferenças e as particularidades de cada organização, insistindose sempre em conservar as regras iniciais dos métodos inalteradas. Isto permite pouca flexibilidade e deixa pouco espaço para negociações entre os grupos, aumentando os conflitos, conforme mostra o diagrama 1.

O segundo conceito de mudança organi-

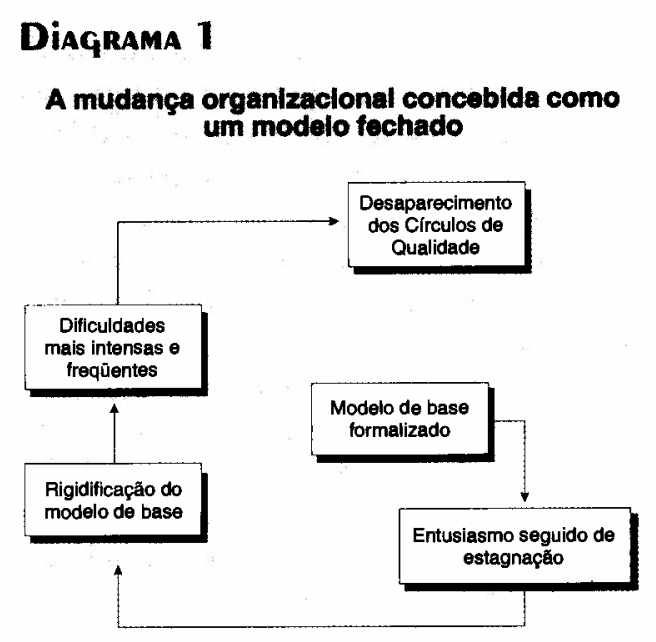

zacional é muito mais flexível: aplica-se inicialmente o método padrão, mas pouco a pouco adapta-se esse método às características particulares da organização e aos seus objetivos, conservando-se, no entanto, as suas principais características. Há um acompanhamento ativo por parte da direção, que observa os problemas suscitados pela implementação inicial do programa e corrige pouco a pouco os desvios observados, adaptando o método e reajustando os outros setores, permitindo negociações entre os grupos etc., conforme pode-se observar no modelo representado no diagrama 2.

A primeira concepção de mudança implica o conceito de que os homens e a organização devem adaptar-se sempre a um modelo intelectualmente superior, construído a priori, que permitirá a abertura de novas perspectivas e a evolução da empresa. É a mudança imposta em nome da eficiência organizacional, através de critérios

\section{Diagrama 2}

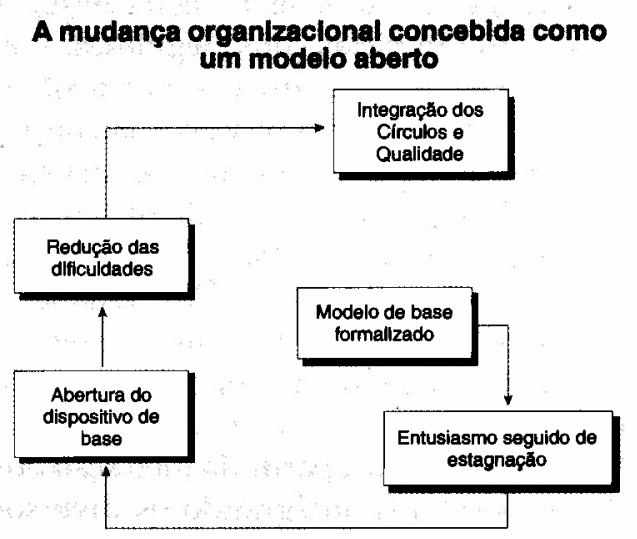


baseados na racionalidade econômica. Os problemas e as resistências suscitados pelo programa são justificados como sendo típicos da gestão de recursos humanos, uma vez que os indivíduos "sempre resistem às mudanças, apegam-se a hábitos arraigados $e$ não entendem a lógica do programa", não partilhando os mesmos critérios de racionalidade econômica defendidos pela direção. Neste caso, a direção busca socializar os indivíduos através de programas de formação, convencendo-os de que sua posição está correta, incitando-os a colaborar. Sua tarefa é "esclarecer" os recursos humanos e transformar o sistema, para que ele seja mais eficaz. Esta lógica levou, no entanto, à uma rigidez do sistema e à extinção dos Círculos de Qualidade. É um modelo que permite duas alternativas aos empregados: ou aderir ao novo método, ou

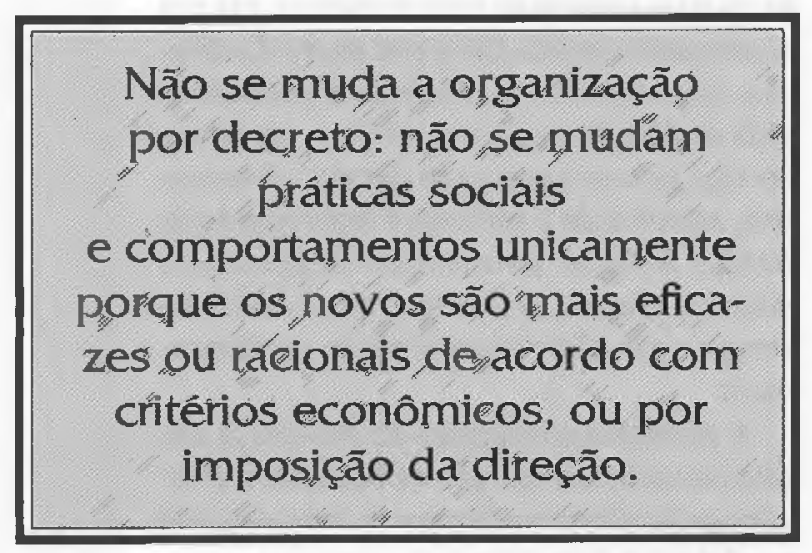

Tradução e adaptaçăo de Isabela Freitas Gouveia de Vasconcelos, revista por Maria Irene Stocco Betiol, Professora do Departamento de Fundamentos Sociais e Jurídicos da Ad̛ministração da EAESP/FGV. A direçāo nāo pretende impor um model fechado de forma dogmática, mas permitir que ele evolua a partir da interação dos diversos setores, integrando os diversos métodos a partir da criaçāo de um sistema maior.

Năo existe, assim, os que estão "contra" ou "a favor" dos Círculos de Qualidade, como no primeiro caso: a existência dos Círculos năo é questionada, uma vez que se aceita a idéia de transformação e adaptaçāo. Os Círculos de Qualidade foram utilizados por essas empresas como um método de transiçăo de uma organização fechada para uma organização mais aberta, consolidando-se um sistema participativo mais amplo através de um processo de aprendizagem organizacional de novas formas de negociaçāo e adaptação.

A aprendizagem de novas práticas sociais no interior da organização e a criação de um sistema participativo com a efetiva integração dos indivíduos são conquistas que levam um certo tempo para concretizarem-se e que dependem da efetiva aplicação de métodos que favoreçam o exercício dessas novas práticas e que incentivem a participação. Os Cúrculos de Qualidade tiveram o mérito de permitir o efetivo desenvolvimento de atitudes mais abertas e participativas, e a sua integração ao sistema. Não se muda a organização por decreto: não se mudam práticas sociais e comportamentos unicamente porque os novos são mais eficazes ou racionais de acordo com critérios econômicos, ou por simples imposição da direçāo. Deve-se permitir aos indivíduos construirem juntos, sob orientação da direção, essas novas práticas participativas, adaptando o método e encontrando soluçōes para os problemas através de negociaçōes entre os diversos departamentos e grupos. Somente dessa forma poderāo consolidar-se as mudanças desejadas e o programa dos Círculos de Qualidade pode ter sucesso, integrando-se nas práticas cotidianas da empresa. Caso contrário, a diretoria provavelmente justificará o fracasso dos Círculos de Qualidade dizendo que eles foram "mais um fenômeno de moda na Administração de Empresas, que nāo poderia durar ", o que não corresponde necessariamente à realidade, como tivemos oportunidade de comprovar nesta pesquisa.

\section{1}

